PRODUCTION

PLANNING \&

CONTROL

THE MANAGEMENT OF OPERATIONS

\section{Production Planning \& Control}

The Management of Operations

\title{
Global product development projects: measuring performance and monitoring the risks
}

\section{Thomas Paul Taylor \& Saeema Ahmed-Kristensen}

To cite this article: Thomas Paul Taylor \& Saeema Ahmed-Kristensen (2018) Global product development projects: measuring performance and monitoring the risks, Production Planning \& Control, 29:15, 1290-1302, DOI: 10.1080/09537287.2018.1520315

To link to this article: https://doi.org/10.1080/09537287.2018.1520315

册Published online: 28 Jan 2019.

Submit your article to this journal $\pi$

山 Article views: 76

View Crossmark data $₫$ 


\title{
Global product development projects: measuring performance and monitoring the risks
}

\author{
Thomas Paul Taylor ${ }^{\mathrm{a}}$ and Saeema Ahmed-Kristensen ${ }^{\mathrm{b}}$ \\ ${ }^{a}$ Management Engineering, Technical University of Denmark, Lyngby, Denmark; ${ }^{b}$ Dyson School of Design Engineering, Imperial College \\ London, London, UK
}

\section{ABSTRACT}

This article investigates the development and application of key performance indicators for global product development. Two in-depth, longitudinal case studies with multinational Danish manufacturing companies were conducted, and highlight how key performance indicators, typically used for collocated, cross-functional product development, do not provide the predictive insight required to avoid the additional risks encountered in the global product development environment. Grounded in the case study results and building on established methodologies in performance measurement literature, a framework was developed and validated in two additional Danish companies to support project managers to develop: preventive indicators, which support the avoidance of identified risks, and outcome indicators, which support the measurement towards the attainment of project objectives. The study is unique as it is one of the very few longitudinal studies of engineering design activities in a global context, providing the in-depth contextual understanding towards key risks and their influence on performance; an important step to support researchers and practitioners with the development of preventive measures.
ARTICLE HISTORY

Received 1 March 2016

Accepted 16 July 2017

KEYWORDS

Global product

development; key

performance indicators; performance measurement; risk management

\section{Introduction}

The establishment of global production sites in low-cost regions is a key force inducing a more recent trend in western manufacturing companies - the global distribution of product development (GPD). This represents a major transformation in industry as companies switch from managing engineering teams, which were previously collocated and cross-functional, to managing teams that are geographically dispersed and culturally diverse to develop products in a collaborative manner. Companies often pursue GPD given the opportunity to gain access to local knowledge in global markets, increase their customer base, access skilled engineers in low-cost regions and reduce overall PD costs (Christodoulou, Fleet, and Hanson 2007; Eppinger and Chitkara 2009). However, recent studies indicate how management have underestimated the cost penalties companies face when operationalizing GPD (Eppinger and Chitkara 2009) and companies have been observed to adopt a learning-by-doing approach, with solutions to problems implemented on an ad-hoc basis (Hansen and Ahmed-Kristensen 2011); described as a typical sign of failure in GPD (Amaral, Anderson, and Parker 2011).

To support the operationalization of GPD, several authors recommend the development of key performance indicators (KPIs) to monitor both positive and negative influences on performance and support the avoidance of deviations before they arise (Christodoulou, Fleet, and Hanson 2007; Hansen and Ahmed-Kristensen 2011). The development and application of KPIs is a topic that has received much attention in the operations management field for business processes in general (Folan and Browne 2005; Ishikawa and Smith 1972; Kaplan and Norton 1992; Neely et al. 2000). However, although there are several studies that investigate this in collocated, cross-functional PD (Costa et al. 2014; Driva, Pawar, and Menon 2000; O'Donnell and Duffy 2002) research towards performance measurement within the context of GPD remains relatively underdeveloped. Developing this understanding is important to support management to overcome the difficulties and inform the development of practical frameworks to better manage GPD.

This article contributes to the further understanding towards the development of KPIs, and how KPIs support the avoidance of risk in the context of GPD. A framework is developed and validated in industry, which supports project managers with the development of KPIs for the avoidance of identified risks and the measurement of project outcomes. The article begins by reviewing the literature in two domains, namely global product development and performance measurement, highlighting the main gaps in the literature to date. The research approach is described and results from two longitudinal case studies with Danish manufacturing companies develop understanding towards how KPIs are developed and used in GPD projects. Based on the results, a KPI development framework is developed and validated in two additional company case studies. The implications for researchers and practitioners are discussed. 


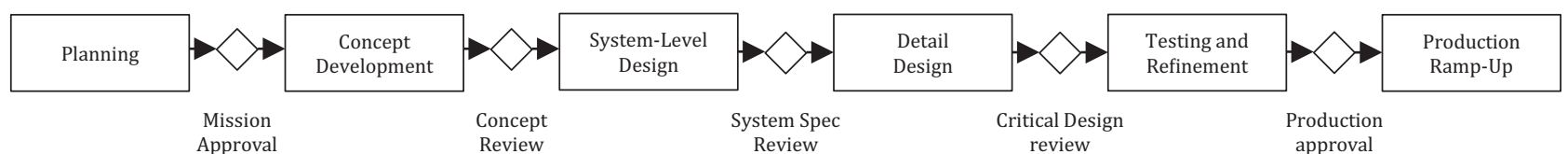

Figure 1. The generic product development process (Ulrich and Eppinger 2011).

\section{Literature review}

The theoretical underpinning of this article draws on two fields of study, namely engineering design where the process of GPD is described and the key risks companies encounter are highlighted; and operations management where performance measurement and the development of KPIs for business processes, in general, are reviewed.

\subsection{Global product development}

For a company to conceive, design and commercialize a product, a PD process comprising a sequence of stages and gates is often employed, from early planning through to final testing and refinement before production ramp-up (Figure 1). GPD is defined as the globalization of tasks and activities throughout the PD process, which typically begin with production and later moves towards the higher value adding stages at the front end of PD (Hansen and AhmedKristensen 2011). There are two terms used to describe the different sourcing modes a company adopts for GPD, namely offshoring, the company expands PD to foreign countries while maintaining full ownership and control of the subsidiary; and outsourcing, the company hands over specific tasks and activities during PD to independent foreign providers (Eppinger and Chitkara 2009).

\subsection{The risks companies encounter}

In this article, we adopt the notion of risk as being a factor or event that has a negative influence on a desired outcome (Browning et al. 2002) and consequently an important contributor to overall performance. Table 1 presents some of the key risks manufacturing companies face when pursuing GPD. The risks are interrelated and often emerge from the difficulties companies face with the management of highly heterogeneous, geographically dispersed engineering teams. For example, previous studies highlight how issues related to conflict resolution (Bierly, Stark, and Kessler 2009), building trust (Bunduchi 2013) and developing shared understanding (Cash, Dekoninck, and Ahmed-Kristensen 2017) become more difficult to manage in environments where distance between teams is increased and frequent, spontaneous interactions are reduced. Furthermore, the distance between teams has been found to have a significant impact on coordination efficiency in relation to adherence to project schedules, budget and completion of tasks (Mcdonough, Kahn, and Griffin 1999). Crabtree, Fox, and Baid (1997) found that activities involving coordination in GPD projects occupied $69 \%$ of an engineer's time, and Littler, Leverick, and Bruce (1995) highlighted how the maintenance of the collaborations often becomes the prime objective rather than the development of the product itself. In addition, although the inclusion of skilled engineers from low-cost regions may provide access to new expertise and reductions in labour costs, the differences among power distribution, uncertainty avoidance and value orientation in relation to national culture can be profound (Hofstede, Hofstede, and Minkov 2010; Schein 2004). Cultural misunderstandings have been found to be a key cause for design rework, quality issues and time delays during GPD in several studies (Hansen and Ahmed-Kristensen 2011; Kalyandurg and Akhilesh 2012; McDonough, Kahn, and Griffin 1999). Although companies often pursue GPD given the opportunities to reduce PD costs, increase their customer base or gain access to new competencies and expertise (Aberdeen Group 2005; Büyüközkan and Arsenyan 2012), altering the environment where PD takes place presents management with additional risks that have adverse effects on GPD performance at the operational level.

Several studies in the literature offer strategic guidelines towards how management can overcome the risks illustrated in Table 1 in relation to the management of virtual teams (Siebdrat, Hoegl, and Ernst 2009), the successful deployment of GPD (Eppinger and Chitkara 2009) and distributed PD (Amaral, Anderson, and Parker 2011). In addition to these studies, Hansen and Ahmed-Kristensen (2012) proposed the Global Decision-Making framework to support the operationalization of GPD. The framework consists of the following five stages: (1) Strategic goal setting; (2) Strategic planning; (3) Operational planning; (4) Implementation phases; and (5) Evaluation. Central to operationalizing, the framework is the inclusion of key performance indicators (KPIs) which provide continuous feedback both in relation to long-term goals for GPD, but also for short-term planning to support the identification and avoidance of key risks as they arise. The importance of developing KPIs for monitoring progress in GPD is further supported in the literature (Cánez, Platts, and Probert 2000; Christodoulou, Fleet, and Hanson 2007). However, to the authors' knowledge, the development and application of KPIs in the context of GPD has received less attention. To investigate this, the following section draws on performance measurement literature in the operations management field.

\subsection{Performance measurement: the development and application of KPIs}

Performance is defined as the effectiveness and efficiency of a process with the purpose of achieving a fixed objective or set of goals (Kaplan and Norton 1996; Neely et al. 2000). The measurement of performance requires a performance measurement system, with the critical element being a 
Table 1. Key risks in GPD from several sources in the literature.

\begin{tabular}{|c|c|c|}
\hline Authors & Risks & Example \\
\hline Hansen and Ahmed-Kristensen (2011) & Cultural differences & $\begin{array}{l}\text { Contrasting levels of autonomy in project team due to } \\
\text { cultural background. }\end{array}$ \\
\hline Mcdonough, Kahn, and Griffin (1999) & Physical proximity & $\begin{array}{l}\text { Collaboration of engineering teams across multiple } \\
\text { time zones. }\end{array}$ \\
\hline Mcdonough, Kahn, and Griffin (1999) & Difficulties with communication & $\begin{array}{l}\text { Spontaneous, face-to-face communication is reduced due } \\
\text { to geographical dispersion of development sites. }\end{array}$ \\
\hline Bierly, Stark, and Kessler (2009) & Trust & $\begin{array}{l}\text { Increased reliance on virtual collaboration makes conflict } \\
\text { resolution challenge, which impacts the level of trust. }\end{array}$ \\
\hline Crabtree, Fox, and Baid (1997) & Difficulties with documentation & $\begin{array}{l}\text { Transfer of company documentation to digital platform } \\
\text { accessible to global partners. }\end{array}$ \\
\hline Cash, Dekoninck, and Ahmed-Kristensen (2017) & Lack of common vision & $\begin{array}{l}\text { Lack of face-to-face interaction creates difficulties for } \\
\text { developing shared understanding. }\end{array}$ \\
\hline BusinessWeek Research Services (2006) & Protection of Intellectual property rights & $\begin{array}{l}\text { Ideas and inventions can be compromised when shared } \\
\text { with parties outside of the company. }\end{array}$ \\
\hline Carmel, Dedrick, and Kraemer (2009) & Knowledge sharing & Difficulties sharing uncodified knowledge virtually. \\
\hline Eppinger and Chitkara (2009) & Coordination & $\begin{array}{l}\text { Global dispersion of activities creates coordination } \\
\text { inefficiency. }\end{array}$ \\
\hline Tripathy and Eppinger (2011) & Standardisation of tools and processes & $\begin{array}{l}\text { Clarity of company processes in common language } \\
\text { accessible to global partners. }\end{array}$ \\
\hline
\end{tabular}

balanced set of financial and non-financial KPIs (Ford and Sterman 2003), which in this article are defined as quantifiable metrics that help an organization measure the success of critical factors. The type of KPIs used for measuring performance relies heavily on the context to which they should operate; hence, it is difficult to determine a set of generalizable KPIs applicable for different situations. As such, much of the research has focussed on how to support the process for developing KPIs for business processes in general. The most recognizable work of this kind was the development of the Balanced Scorecard (Kaplan and Norton 1992), which aims to frame the development of KPIs according to four perspectives, namely financial; customer; internal business; and innovation and learning. However, the framework has frequently been referred to as a strategic management tool rather than a tool to support the development of KPIs specifically (Neely, Gregory, and Platts 2005; O'Donnell and Duffy 2002). As part of their work on performance measurement system design, Neely et al. (2000) proposed the following desirable characteristics for designing KPIs:

1. Indicators should be derived from the company's strategy

2. The purpose of the indicator must be made explicit

3. Data collection and methods of calculating performance must be clear

4. All stakeholders must be involved in the selection of the indicators

5. The indicator should take account of the organisation

6. The indicators should change as circumstances change.

Building on these characteristics, Folan and Browne (2005) proposed a framework that provides a systematic process for the selection of KPIs in extended enterprises. A key element to the framework is the early identification of critical success factors for the business as an approach for developing purposeful KPIs. Furthermore, Mendibil and Macbryde (2007) developed a framework that aims to support the development of KPIs that focus on team-based performance measurement, which encourages the selection of KPIs according to key drivers of team performance. Although the frameworks were developed for business processes in general, the fundamental principles may be transferable to the environment of GPD.

A commonality within the aforementioned frameworks and the performance measurement literature, in general, is the tendency to develop KPIs according to whether they focus on measuring an outcome of a process or whether they monitor factors influencing the outcome of a process. For example, Kaplan and Norton (1996) identified two distinct types of KPIs: lagging KPIs, which measure the output of past activity and typically consist of financial indicators; and leading KPIs, which measure factors influencing a process and are drivers of performance. Rhodes, Valerdi, and Roedler (2009) stated that 'contrary to simple status oriented measures typically used on most projects, leading indicators are intended to provide insight into the probable future state, allowing projects to improve the management and performance of complex programs before problems arise'. Similarly, Ishikawa and Smith (1972) discussed the notion of feedforward control, which is defined as 'anticipatory control in which preventive action is taken before the difference between planned and actual performance occurs'. Considering performance measurement as a feedback loop to support the development of preventive action, Wang, Lin, and Huang (2010) highlighted the importance of developing risk-oriented measures, particularly in environments of high uncertainty, to support the avoidance of identified risk and increase the likelihood of project success. The different classifications highlight the importance of developing KPIs that not only focus on the outcome of past activity but also focus on identifying problems that influence performance along the process and hence support the avoidance of deviations. O'Donnell and Duffy (2002) stated that obtaining values for performance is in itself worth less if the factors that influence these values cannot be identified. Despite this, a general criticism towards KPIs in collocated, cross-functional PD (conventional PD) is they provide a retrospective, time delayed evaluation of performance and focus on the more tangible outcomes such as adherence to project schedules, budgetary 
requirements and the quality of the final product (Driva, Pawar, and Menon 2000; Rhodes, Valerdi, and Roedler 2009; Tatikonda 2007). Furthermore, O'Donnell and Duffy (2002) highlighted that existing approaches for performance measurement in conventional PD almost exclusively focus on the performance of the design artefact (the outcome) and not the performance of the activities required for its development (the process). For example, they do not consider the trade-off between the cost of the PD process and the quality of the final product. While developing KPIs according to time, cost and quality is important - a traditional approach to performance measurement in the project management literature (Krishnan and Ulrich 2001), the dimensions have been found to neglect the importance of the dynamic nature of PD in varying contexts (Snider et al. 2016; Toor and Ogunlana 2010).

\subsection{Summary and research questions}

Despite several calls for research towards the development and application of KPIs in the context of GPD (Büyüközkan and Arsenyan 2012; Hansen and Ahmed-Kristensen 2011; Mendibil and MacBryde 2007; Tripathy and Eppinger 2011), research towards this topic remains relatively underdeveloped. Altering the environment where PD takes place brings rise to additional risks that influence performance and traditional approaches for developing and using KPIs found in conventional PD or for business processes, in general, may not be practical for GPD. As such the research sought to answer the following research questions:

1. What are the KPIs used for measuring performance in GPD, and how are these developed?

a. How do the KPIs support the avoidance of key risks in GPD?

2. How can the process of developing and documenting KPIs be supported in GPD?

The research approach to investigate the research questions is described in the following section.

\section{Methodology}

The aim of the research was two-fold: first, to develop an understanding towards the development of KPIs, and how the KPIs support the avoidance of key risks encountered in GPD projects; and second, to design a method to support the development and documentation of KPIs for GPD projects. The research approach for the second aim of this article is described in Section 5. To address the first aim, longitudinal case studies with two, multinational Danish manufacturing companies were carried-out. First, 21 semi-structured interviews were conducted to provide understanding towards KPIs selected for GPD projects, and the process for developing these. Second, 34 non-participatory observations of two, real-time GPD projects were conducted to provide the in-depth contextual understanding necessary to investigate how KPIs were used to support the avoidance of key
Table 2. Company characteristics.

\begin{tabular}{|c|c|c|}
\hline Characteristics & Company A & Company B \\
\hline Headquarters based in & \multicolumn{2}{|c|}{ Denmark } \\
\hline Industry sector & $\begin{array}{l}\text { Refrigeration and } \\
\text { air conditioning }\end{array}$ & Pharmaceutical \\
\hline No. of employees & 24,000 & 2700 \\
\hline $\begin{array}{l}\text { Offshored R\&D facilities involved in } \\
\text { the study }\end{array}$ & India & China \\
\hline $\begin{array}{l}\text { No. years offshored R\&D established } \\
\text { at the time of the study: }\end{array}$ & 2.5 & 1.5 \\
\hline
\end{tabular}

risks encountered. Case studies were considered appropriate given the exploratory nature of the research questions and the opportunity to gain in-depth understanding towards real-time tasks and activities in industry, which leads to creative insights of high validity for practitioners (Voss, Tsikriktsis, and Frohlich 2002). The case studies are described in the following sections together with the method for data collection and analysis.

\subsection{Description of case studies}

Characteristics of the two case studies are presented in Table 2. The companies were selected based on the following criteria important for the fulfilment of the research aim: (1) the recent establishment of offshore R\&D facilities in lowcost countries such as China and India; and (2) the high involvement of engineers located at the offshore R\&D facilities during the development of products.

\subsubsection{Company $A$}

The company specialize in the production of industrial valves and controls for the refrigeration and air conditioning markets. Recently, the company established an offshore R\&D facility in India with the motivation to reduce PD costs by gaining access to low labour costs of skilled engineers in India. However, the company encountered difficulties with the collaboration as a number of tasks, such as the conversion of old product drawings to computer-aided design (CAD) systems that were considered routine in nature, were neither completed on time nor to the desired quality by the Indian engineers. The lack of motivation of the skilled Indian engineers to work on routine tasks was considered a key contributing factor to the difficulties and as such, the company decided to involve the Indian engineers as the 'main drivers' in a more complex GPD project to increase motivation. The GPD project forms the basis for the observations reported at Company $A$ and the project is further described here.

The objective of the GPD project was to improve the performance of an existing valve by increasing the product lifetime. The project was introduced to the Indian engineers as a 'Pilot' project with the primary aim to improve the collaborations. The solution was known by the Danish engineers to reduce the risk of project failure. The project was expected to last 3-4 months and followed the stages in the standard PD process at the company (Figure 2), comparable to a 


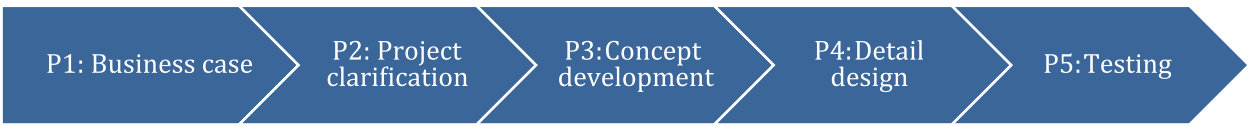

Figure 2. PD process at Company A.

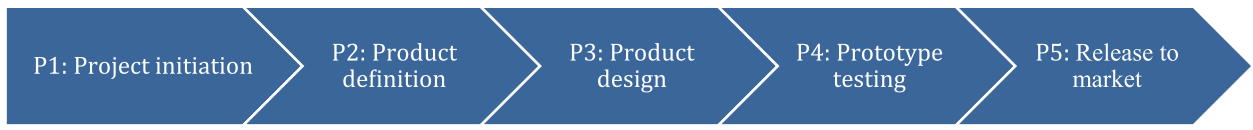

Figure 3. PD process at Company B.

generic stage-gate process described in the literature (Ulrich and Eppinger, 2011).

\subsubsection{Company $B$}

The company specialize in the development and manufacture of blood analysis instruments, such as blood gas analysers and syringes for the pharmaceutical industry. The company operates globally and recently established an $R \& D$ facility in China with the motivation to reduce PD costs. A GPD project between the Danish and Chinese engineers forms the basis for the observational studies reported at Company $\mathrm{B}$ and is further described here.

The objective of the project was to develop a new blood gas analyser, enabling doctors and nurses to retrieve more blood samples in a given period. It was critical that the 18month project time frame was adhered to ensure the product was released to market before their component suppliers could develop a similar product. The project followed the stages in the standard PD process at the company (Figure 3) and was comparable to a generic stage-gate process described in the literature (Ulrich and Eppinger 2011).

\subsection{Data collection}

The interviews and observations conducted at the two companies are presented in Tables 3 and 4, respectively. Company participants primarily consisted of design engineers from the Danish headquarters and global R\&D facilities. Toplevel management from the Danish headquarters was also involved on a less frequent basis during the observed GPD projects.

For the interviews, a guide was developed based on the research aim that focussed on understanding the KPIs selected for GPD projects, and how the KPIs were developed. The interviews were conducted face-to-face with the Danish engineers and online using a video conference tool with the geographically dispersed engineers. The interviews were audio recorded, transcribed and transferred to a coding scheme (described in Section 3.3) for further analysis.

For the observations, key meetings during the GPD projects were observed at different stages along the PD process at the two companies. As members of the project teams were geographically dispersed, the meetings were held online using a video conference tool. The researcher did not actively participate during the meetings. At Company $A$, the GPD project was observed from the 'Business case' stage
Table 3. Semi-structured interviews conducted at Company A and Company B.

\begin{tabular}{lcc}
\hline Interviews & Company A & Company B \\
\hline No. of interviewees: & 12 & 9 \\
Nationality: & $8 \times$ Danish, $4 \times$ Indian & $3 \times$ Danish, $6 \times$ Chinese \\
Interview length: & & $45-60$ min
\end{tabular}

Table 4. Non-participatory observations conducted at Company A and Company B.

\begin{tabular}{lcc}
\hline Observations & Company A & Company B \\
\hline No. of observations: & 24 & 10 \\
Hrs. of observations: & 27 & 19 \\
No. of participants: & 10 & 9 \\
Time span of observations: & 8 months & 4 months \\
\hline
\end{tabular}

through to the final 'Testing' stage (Figure 2). Due to time restrictions, the GPD project at Company B was observed from the 'Project initiation' stage through to the 'Product design' stage (Figure 3). Confidentiality agreements prohibited the researcher from recording all project meetings. Field notes structured according to the research aim were taken and transferred to the coding scheme for further analysis.

\subsection{Data analysis}

A coding scheme for analyzing the data collected was developed based on (1) key theoretical concepts from the literature review; and (2) key insights that emerged from the empirical studies. Key aspects of using thematic analysis as described by Braun and Clarke (2006) supported this process. An example of how the data was coded is provided here.

The transcripts from the interviews and field notes from the observations were analyzed, a few lines at a time, and categorized according to themes. For example, if a participant from the study stated a KPI used in GPD projects, this would be categorized within the theme 'KPIs'. Once the transcripts and field notes had been categorized according to the broad themes, sub-codes within these themes were created to identify interesting patterns. For example, if the KPI stated was related to measuring the cost of PD, the sub code 'PD cost' was created within the theme 'KPIs'. Codes were developed from the literature review where possible. However, research towards performance measurement in GPD is relatively under developed and as such, codes were also developed from the empirical data as the study progressed. The categorization of the transcripts within themes and sub-codes was an iterative process. The codes were counted for frequency of occurrence to identify key patterns 
Table 5. KPIs selected for GPD projects at Company A and Company B.

\begin{tabular}{|c|c|c|c|c|}
\hline Performance dimensions & $\mathrm{KPI}$ & Definition & Company A & Company B \\
\hline \multirow[t]{4}{*}{ Development cost } & Cost of PD & Estimated resources required for $\mathrm{PD}$ & $\checkmark$ & $\checkmark$ \\
\hline & Return on investment & Yearly cost savings after investment & $\checkmark$ & $\checkmark$ \\
\hline & Planned vs Actual resources & Difference between expected and actual resources used & $\checkmark$ & \\
\hline & Cost of delay & Financial implications of project time delays & & $\checkmark$ \\
\hline Development time & Project lead time & Amount of time from project initiation to completion & $\checkmark$ & $\checkmark$ \\
\hline \multirow[t]{2}{*}{ Product quality } & No. of product lifecycles & Durability of the product throughout its lifespan & $\checkmark$ & \\
\hline & Customer satisfaction & Usability of product prototypes & $\checkmark$ & $\checkmark$ \\
\hline \multirow[t]{5}{*}{ Other } & Documentation errors & Number of errors in drawings completed by global engineers & $\checkmark$ & \\
\hline & Documentation approval time & Time taken to approve documents by internal board & & $\checkmark$ \\
\hline & Document approval delays & Number of days delayed due to document approval time & & $\checkmark$ \\
\hline & Internal design expert feedback & Feedback from design experts at the company (external from the project) & $\checkmark$ & \\
\hline & Feedback on assembly & Feedback from the supplier towards product design & $\checkmark$ & $\checkmark$ \\
\hline
\end{tabular}

Risk identification

KPI measurement: internal design feedback (retrospective)

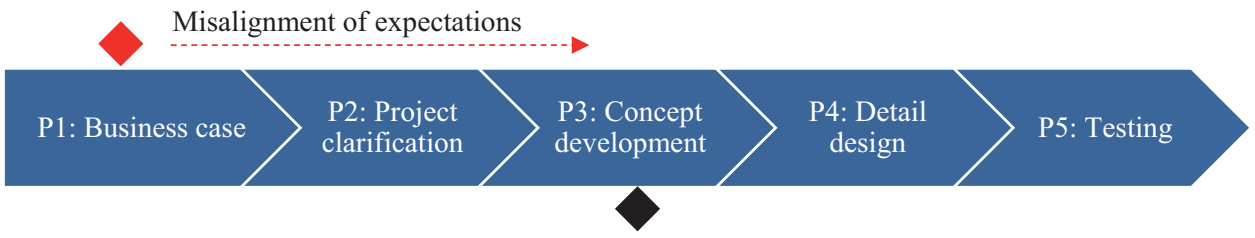

Figure 4. KPIs for monitoring risk at Company A.

and relationships within the data. Following the frequency counts, the qualitative analysis of the patterns indicated provided an understanding of the rationale and theory underlying relationships.

\section{Findings}

The approach for developing KPIs at Company $A$ and Company $B$ is outlined followed by the KPIs selected for GPD projects. Implications of using the KPIs are then discussed in relation to the observed GPD projects.

\subsection{The approach for developing key performance indicators}

At Company A, KPIs for GPD projects were selected according to the tasks outlined in the PD process by the Danish project manager. For example, at the 'Business case' stage KPIs were selected when determining budgetary requirements, project schedules and pre-defined product quality requirements, which were aligned with high-level KPIs at the company. The GPD team was not involved when selecting $\mathrm{KPIs}$, despite the importance highlighted in the literature of including key stakeholders when developing KPIs (Neely et al. 2000). The implications of this are discussed in the following sections. At Company $\mathrm{B}$, the Danish project manager held a workshop during the 'Project initiation' stage that focussed on the selection of KPIs for the observed GPD project. During the workshop, the Chinese engineers were collocated at the Danish R\&D facility. The primary approach for selecting KPIs was a brainstorming session where team members were asked to state KPIs they would like to work with during the project whilst adhering to high-level KPIs at the company, such as project schedule and costs, customer satisfaction and product quality. However, the lack of knowledge and experience towards KPIs in the team impacted the level of commitment during the workshop and few actively participated. Although brainstorming is a useful technique for exploring the factors important for measurement (Neely et al. 2000), its application for developing purposeful and measurable KPIs has been criticized (Barr 2014).

\subsection{Key performance indicators for global product development projects}

Table 5 presents the KPIs selected for GPD projects across the two companies. It was possible to group the KPIs according to three performance dimensions described as important for conventional PD projects, namely development cost, development time and product quality. This can largely be explained given the adherence to the high-level KPIs at the companies, when selecting the KPIs, and implies that KPIs for conventional PD projects are also important for GPD projects. However, a criticism towards KPIs in conventional PD projects is they are retrospective in nature; hence, inform management of deviations once it is too late to implement change (Rhodes, Valerdi, and Roedler 2009). Furthermore, many of the KPIs relate to financial targets, which are typically described as lagging KPIs (Kaplan and Norton 1996), and reaffirms previous studies that highlight how practitioners in PD select KPIs according to tangible outcomes (Tatikonda 2007). The 'Other' KPIs, which were not directly related to the performance dimensions, focus on monitoring issues in relation to documentation and feedback towards product design. The application of the KPIs in Table 5 is discussed within the context of the observed GPD projects in the following section. 


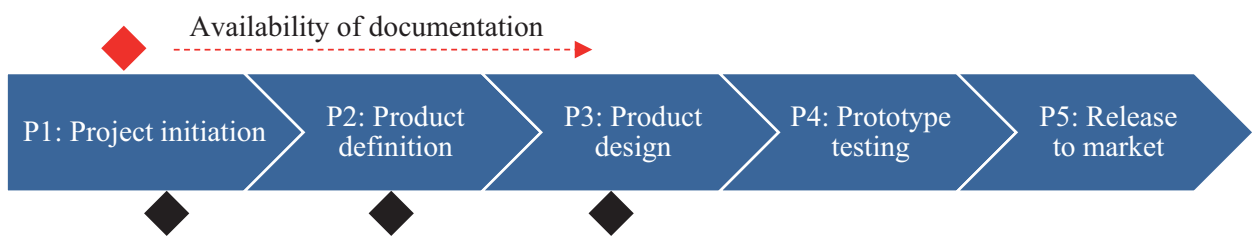

Figure 5. KPIs for monitoring risk at Company B.

\subsection{Monitoring the key risks in global product development projects}

At Company A, the Indian engineers were included as the 'main drivers' in a more complex GPD project, from the early business case preparations through to the final testing, to increase motivation among the Indian engineers (see Section 3.1.1 for project background). Despite the increased level of responsibility, the GPD project was introduced as a 'Pilot' project with the primary aim of improving collaborations while keeping resource consumption low. The Indian engineers were aware of the project conditions; however, they attempted to increase the value of the project by proposing a large number of solutions that would influence additional product variants outside the project scope. The propositions were rejected by the Danish engineers at the end of the 'Concept development' stage, as they were considered too ambitious given the solution they had in mind. The misalignment of expectations resulted in design rework and was a key contributor for the project being delayed by over two and a half months. In this example, the project manager used the KPI 'Internal design expert feedback' (Table 5) to measure the quality of solutions proposed by the Indian engineers. However, the KPI was used at the end of the 'Concept development' stage, at which point the additional time for developing the solutions had already been used by the Indian engineers. During the 'Business case' stage, the likelihood and impact of the misalignment of expectations within the project team were identified as a key risk while conducting a project risk assessment. Despite this, the KPI selected did not provide the necessary feedback in relation to the misalignment of expectations to avoid the subsequent time delays. Figure 4 illustrates the risk identification and point of measurement according to the PD process at Company A. The KPI provided insight towards how to avoid the misalignment of expectations in future GPD projects; however, it did less to support the avoidance of project time delays in the current GPD project.

An additional factor contributing to project time delays was the lack of adherence to the PD process in the project team. For example, rather than structuring project activities according to requirements in the PD process, as requested by the Danish project manager, the Indian engineers adopted a Six Sigma process they had recently received training into structure project work. This resulted in a significant amount of time being used by the project manager in re-aligning tasks completed by the Indian engineers according to the requirements in the PD process. The lack of adherence to the PD process was not identified as a key risk impacting project timing and was not considered when selecting KPIs for the project. The impact of the risk was first realized when measuring the KPI 'Planned vs actual resources' (Table 5), which did not provide the predictive feedback required to avoid time delays as a result of the risk.

The influence that the misalignment of expectations and adherence to the PD process had on project timing was not anticipated at Company A and KPIs to support the avoidance of deviations were not developed. An explanation for this could be the lack of involvement of the GPD team during the selection of KPIs and the difficulties with developing KPIs to measure intangible risk factors. However, selecting KPIs according to common performance dimensions in PD such as time, cost and quality appear inadequate to avoid risks encountered in the GPD environment.

At Company B, adherence to project schedules was critical for the GPD project to avoid the risk of component suppliers releasing a similar product (see Section 3.1.2). As such, during the KPI selection workshop, the Chinese engineers voiced their concerns regarding the availability of project documentation as a potential cause for project time delays, given the physical distance between themselves and the Danish engineers. A key factor contributing to the availability of documentation was identified to be the time taken for documents to be approved and released to the Chinese R\&D facility and as such, the KPI 'Document approval time' (Table 5) was developed to prompt the team to take action when the expected approval time for project documents was exceeded. Figure 5 illustrates the risk identification and point of measurement for the KPI according to the PD process at Company B. The KPI provided the necessary insight to avoid time delays due to the time taken to approve documentation in the current GPD project. Involving the GPD team and identifying key cause-effect relationships, which influenced the adherence to project schedules, was an important process for developing KPIs to avoid deviations.

The two case studies provide understanding towards the development of KPIs, and how the KPIs support the avoidance of risks in GPD projects. To summarize, the key findings from the case studies were:

- KPIs developed according to common performance dimensions in conventional PD do not support the avoidance of key risks, such as a misalignment of expectations 
Stage I: Key concepts

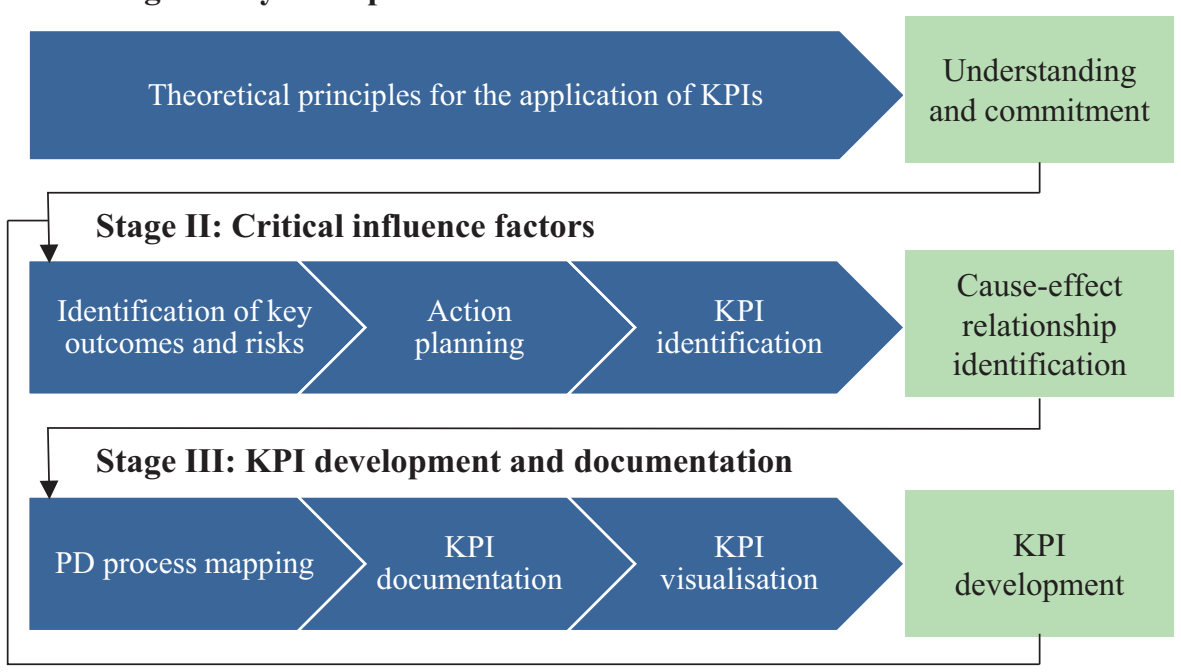

Revise and review

Figure 6. The KPI development framework.

and the adherence to the PD process, encountered in the context of GPD.

- Identifying and understanding the relationship between desirable outcomes, and key risks that influence these outcomes, is an important step for developing KPIs to avoid the risks in GPD projects.

- The lack of structure when developing KPIs impacted the level of commitment and understanding of purpose towards using KPIs in the GPD teams.

\section{Framework development and application}

Based on the findings from the previous section and building on established methodologies from the performance measurement literature (Neely et al. 2000), a framework to support the development of KPIs for GPD projects is presented in the following section. The application of the framework is described in two industrial case studies.

\subsection{The KPI development framework (KPI-DF)}

The KPI-DF aims to support project managers in manufacturing companies with the development and implementation of KPIs in GPD projects. The framework consists of three stages carried out during a 5-hour facilitated workshop. An overview of the three stages is illustrated in Figure 6 and further described in the following section.

\subsubsection{Stage I}

The aim of stage $I$ is to develop commitment and understanding towards the purpose of developing KPIs in the GPD project team. The facilitator exemplifies the importance of performance measurement as a decision support tool and highlights the relationship between KPIs that are retrospective and KPIs that are preventive with industry examples. It is important both the project manager and GPD team participate during stage $\mathrm{I}$.

\subsubsection{Stage II}

The aim of stage II is to identify critical factors important for the achievement of project objectives to support the development of KPIs. First, the facilitator supports the identification and prioritization of desirable outcomes for the project. At this point, the desirable outcomes are to be aligned with high-level KPIs at the company. Second, the facilitator supports the identification and prioritization of key risks that pose a threat towards the achievement of the previously identified desirable outcomes. The facilitator provides key risks common in GPD to support this process (Table 1). Actions are planned for the avoidance of key risks to support the identification of KPIs to monitor intangible risk factors. Planning activities to drive performance has been highlighted as a technique to support the development of KPls (Neely et al. 2002). The project manager and GPD team participate during stage II.

\subsubsection{Stage III}

The aim of stage III is to develop and document the following: (1) outcome KPIs, which measure performance in relation to desired outcomes for the project; and (2) preventive KPIs, which monitor the risks that influence the achievement towards the desired outcomes. The actions planned during the stage II are mapped to the PD process at the company to indicate where along the process they require implementing. Based on this, KPls are developed to drive the implementation of the actions to support the avoidance of risks identified (preventive KPIs) and measure the impact in relation to desirable project outcomes identified (outcome KPIs). The facilitator provides examples of KPIs for GPD to support this process (Table 5). The KPIs are documented according to a KPI template that builds on previous frameworks for desirable KPIs (Neely et al. 2000) to ensure the following: the purpose and formula for measuring the KPIs is understood, the main responsible for measuring the KPIs is outlined and the frequency of measurement and targets are clearly defined. 
Table 6. Company characteristics.

\begin{tabular}{|c|c|c|}
\hline Characteristics & Application I & Application II \\
\hline Headquarters based in: & Denmark & Denmark \\
\hline Industry sector: & Satellite communications & Refrigeration and air conditioning \\
\hline No. of employees: & 900 & 420 \\
\hline Offshored R\&D facilities: & South Africa & China \\
\hline GPD project: & $\begin{array}{l}\text { Develop a radio system to improve } \\
\text { communication speed in aeroplanes }\end{array}$ & Develop single software platform for future GPD project adherence \\
\hline No. participants at workshop: & 8 & 6 \\
\hline
\end{tabular}

Table 7. Example of preventive KPI documented in the KPI template (Application I).

\begin{tabular}{|c|c|}
\hline Key performance indicator & Level of understanding towards company procedures \\
\hline Purpose & Increase level of understanding towards processes and planning \\
\hline Key outcome related to & On-time project delivery \\
\hline Key risk related to & Adherence to company procedures \\
\hline Action plan & $\begin{array}{l}\text { Develop } 5 \text { min survey to test the level of understanding towards company procedures - distribute on a } \\
\text { regular basis }\end{array}$ \\
\hline Calculation (\%of, \#of, \$of, ..) & Scaling system based on a survey - forecasted \% of correct answers vs actual \% of correct answers \\
\hline Forecasted target (weekly/monthly) & To be decided \\
\hline Maximum target (weekly/monthly) & To be decided \\
\hline Measurement frequency & Monthly - results to be shared within the team \\
\hline PD stage & Continuous - the beginning of each stage in the PD plan \\
\hline Data source & Participant results from survey \\
\hline KPI type (outcome/preventive) & $\begin{array}{l}\text { Preventive - identifies where there is a lack of understanding towards processes and hence, allows for } \\
\text { corrective action along the process }\end{array}$ \\
\hline Main responsible & Program management office \\
\hline Notes and comments & $\begin{array}{l}\text { - Different members have different understanding towards processes - requirement for answers in the } \\
\text { survey to be weighted. } \\
\text { - Results from the survey should be populated digitally to ensure a database can be created and ana- } \\
\text { lysed over time. }\end{array}$ \\
\hline
\end{tabular}

Finally, the KPIs are recorded to a KPI visualization board for simple monitoring, which includes the following: line graphs or bar charts to indicate KPI status in relation to forecasted and actual targets, key challenges encountered during measurement and proposed solutions, key achievements and the next steps for measurement. The project manager participates during stage III.

\subsection{Application of the KPI-DF}

For the initial validation of the KPI-DF, two 5-hour workshops that followed the three stages outlined in the previous section were held at two large Danish manufacturing companies. The two companies were selected based on their interest in developing KPIs for GPD projects that they were currently involved in. Table 6 outlines the characteristics of the two companies. The following sections describe the implications of application of the KPI-DF.

\subsubsection{Application I}

An example of a KPI developed during the 5-hour workshop is illustrated in Table 7 according to the KPI template. The allocated time for the workshop was insufficient to complete the KPI visualization board during the stage III. This was primarily due to difficulties encountered during the stage II when aligning expectations between project members with different functional backgrounds. For example, the project manager believed the lack of commitment towards company procedures within the project team was a key risk likely to impact project delivery time: a critical success factor for the project. Alternatively, the software engineer believed the lack of alignment between software and hardware would impact the quality of the final product. Although both were important risks influencing the project outcome, the lack of commitment towards company procedures was deemed the most influential within the team. To mitigate the impact of this risk on project timing it was decided that an internal survey should be developed, which focussed on testing the level of understanding towards company procedures in the project team at specific stages along the PD process. However, the questions developed for the survey required approval from the quality assurance board at the company; therefore, key targets for measuring the understanding towards company procedures could not be formulated during the workshop.

\subsubsection{Application II}

Similar to the previous application, the 5 hours allocated for the workshop during Application II was insufficient for the completion of the KPI visualization board, primarily due to the in-depth discussions within the team in relation to desired outcomes and key risks for the GPD project. Again, the project team consisted of members with different functional and cultural backgrounds and a key technique in aligning expectations was to consider the high-level KPIs at the company. As such, it was deemed that the desired outcome was to ensure on-time project delivery while keeping within budgetary requirements. A key risk influencing these outcomes was identified to be a lack of common vision between the culturally diverse and geographically dispersed 
Table 8. Example of preventive KPI documented in the KPI template (Application II).

\begin{tabular}{ll}
\hline Key performance indicator & Level of participation from key project stakeholders \\
\hline $\begin{array}{l}\text { Purpose } \\
\text { Key outcome related to }\end{array}$ & $\begin{array}{l}\text { Increase communication during the project with key project stakeholders } \\
\text { Key risk related to }\end{array}$ \\
$\begin{array}{l}\text { Action plan } \\
\text { Calculation (\% of, \# of, } \$ \text { of, ...) }\end{array}$ & Set up structured project meetings, in particular during the early stages of PD, with key project stakeholders \\
Forecasted target (weekly/monthly) & Forecasted \% of key stakeholders vs actual \% of key stakeholders present during structured meetings \\
Maximum target (weekly/monthly) & Minimum of 5 key stakeholders present \\
Measurement frequency & N/A \\
PD stage & Every two weeks during early stages and less frequent during the later stages of PD \\
Data source & Project pre-approval, Data collection, Project evaluation \\
KPI type (outcome/preventive) & Project meetings held with key stakeholders \\
Main responsible & Preventive - encourages participation to avoid a lack of common vision between key stakeholders \\
Notes and comments & Project manager \\
& - Who are the key stakeholders \\
& - Meetings should be more frequent during the early PD stages \\
& - Fixed agenda to simplify the collection of feedback
\end{tabular}

GPD team. Therefore, it was decided to set up structured project meetings with key project stakeholders to increase communication and interaction frequency and hence avoid the risk of a lack of common vision within the project team. An example of the KPI developed is illustrated in Table 8 in the KPI template.

\section{Discussion}

The findings are discussed in the following section in relation to the key risks encountered and their influence on project performance, and the application of KPIs in GPD projects. The section concludes by outlining key implications for researchers and practitioners.

\subsection{GPD risks and the influence on project performance}

Risks related to the misalignment of expectations and adherence to the PD process are not exclusive to GPD - they exist in engineering teams that conceptualize, design and develop products in collocated environments. However, in GPD where culturally diverse and geographically dispersed engineers must work collaboratively, such risks become more complex (Amaral, Anderson, and Parker 2011; Emden, Calantone, and Droge 2006). For example, in comparison to conventional $P D$, the geographical dispersion of engineers during GPD reduces communication and interaction frequency and as such, adherence to the PD process becomes increasingly important to avoid coordination inefficiencies (Eppinger and Chitkara 2009). This is reaffirmed in the current study where a lack of adherence to the PD process at Company $A$ resulted in the misalignment of work, increased efforts towards coordination and subsequent project time delays. However, standardizing PD processes that were previously designed to operate lean and efficiently in a local environment, to a format understandable in multiple geographical locations is not an easy task. Furthermore, setting relevant managerial controls while providing global partners with sufficient responsibility towards development tasks remains a unique challenge for GPD. At Company A, the boundaries set in the 'Pilot' project by the Danish management restricted the innovative freedom of the Indian engineers and resulted in a misalignment of interests and subsequent project time delays. Drawing on literature that investigates managerial control in conventional PD, such ramifications do not come as a surprise. For example, when management takes a more directive role in PD projects, i.e. intervening during project decisions and redirecting the project team, Bonner, Ruekert, and Walker (2001) found there to be negative ramifications on project performance. Poskela and Martinsuo (2009) concluded that over framing the problem domain during the early stages of PD can be counterproductive as team members refrain from making more risky decisions. However, previous studies in the GPD literature highlight how companies routinize tasks for their global partners in a bid to stabilize the environment, reduce the risks of project failure and avoid cultural misunderstandings (BusinessWeek Research Services 2006; Hansen and Ahmed-Kristensen 2011). This creates an interesting paradox and while the longitudinal observations provided initial insight to understand the influence of managerial control on GPD project performance, this area of research remains underdeveloped.

Changing the environment from local, cross-functional PD to GPD brings rise to additional risks, and understanding the influence on project performance is an important step to support researchers and practitioners to develop preventive measures.

\subsection{The development and application of KPIs in GPD projects}

A fundamental principle in the performance measurement literature is that for KPIs to be successful they must change as circumstances change (Kaplan and Norton 1996; Neely et al. 2000). With this in mind, selecting KPIs typical for conventional PD projects for GPD projects may not suffice given the additional risks that influence project performance. Exemplified in Company A, KPIs related to budgetary requirements, project time schedules and product quality provided a retrospective look on performance, which was inadequate to avoid the misalignment of expectations, lack of adherence to the PD process, and subsequent project time delays. Such KPIs have been described as important for evaluating the outcome of PD once a project has reached its conclusion (Bonner, Ruekert, and Walker 2001; Tatikonda 2007). Alternatively, and exemplified in Company B, identifying key 
risks, and understanding their influence on project performance, supported the development of KPIs that prompted managerial action to avoid deviations along the process. Such KPIs have been described as preventive and provide insight into the probable future state, allowing management to take action before problems arise (Neely, Gregory, and Platts 2005; Rhodes, Valerdi, and Roedler 2009). Despite the need highlighted to support practitioners to better understand and develop both preventive and outcome KPIs (Neely, Gregory, and Platts 2005; Rhodes, Valerdi, and Roedler 2009); there are few studies in the literature that address this. Given the dynamic environment that characterizes GPD, and difficulties with developing KPIs according to less tangible risk factors, providing a structured approach to support the development of KPIs becomes increasingly important to avoid managers adopting KPIs designed for conventional PD projects alone. The KPI-DF addresses this by supporting:

1. The identification of key risks, and understanding towards how these influence project outcomes

2. The development of strategic action plans mapped to the PD process

3. The design and documentation of preventive KPIs, which support the avoidance of key risks and outcome KPIs, which measure the influence on the desired project outcome.

During the application of the KPI-DF, identifying and understanding relations between key risks and the influence on project outcomes was the most time-consuming stage given the heterogeneity of the GPD teams. However, discussing this in an open forum supported in aligning expectations within the project teams: key risk companies encounter during GPD (Cash, Dekoninck, and Ahmed-Kristensen 2017). Furthermore, designing action plans was an important step to support the development of quantifiable, preventive KPIs to support the avoidance of intangible risk factors. However, the allocated time for future applications of the framework should be extended to ensure the developed KPIs are sufficiently documented to support project monitoring.

\subsection{Managerial and research implications}

The study develops understanding towards the development and application of KPls in the context of GPD projects, which builds on previous studies that investigate this in conventional PD (O'Donnell and Duffy 2002; Tatikonda 2007) and business processes in general (Mendibil and MacBryde 2007; Neely et al. 2000). The following key implications for researchers are outlined:

- KPls that are typically used in conventional PD, such as those related to time, cost and quality, do not provide sufficient feedback to avoid key risks encountered in the context of GPD.

- There is a need to support the development of preventive KPIs in the context of GPD, rather than solely outcome
KPIs typically used in conventional PD, which provide indication towards deviations before they arise.

- Developing understanding towards the key risks in GPD, and their influence on project performance, provides researchers and practitioners with a depository of knowledge that can be used to inform the development of preventive measures.

The following implications are outlined for practitioners:

- The initial application of the KPI-DF implies that the framework can be used to support the development of both: preventive KPIs to support the avoidance of key risks, and outcome KPIs to measure the influence on project outcomes.

- Proactively understanding risks, and their influence on project outcomes, was a valuable step in the KPI-DF that can support the alignment of expectations within project teams.

\section{Conclusion}

This article contributes to the further understanding towards the development of KPIs, and how KPIs are used to support the avoidance of key risks in the GPD environment. While there exist comprehensive studies that investigate performance measurement for business processes in general, the development and application of KPIs in the context of GPD has received less attention. To address this, the results from longitudinal case studies with two, multinational Danish manufacturing companies highlight how KPIs that are typically used in conventional PD, such as those related to time, cost and quality, do not provide sufficient feedback to avoid key risks encountered in GPD. The misalignment of expectations and the lack of adherence towards a standard PD process are key risks that influenced project performance, which reaffirms studies in the literature that highlight how altering the environment of PD brings rise to additional risks (Amaral, Anderson, and Parker 2011; Emden, Calantone, and Droge 2006). In the context of GPD, there exists a need to proactively understand risks, and their influence on project performance, and develop KPIs that provide the predictive insight necessary to avoid deviations before they arise. Based on this, the KPI-DF was developed and validated in two additional Danish manufacturing companies. Initial results indicate that the framework supports project managers to develop KPIs for the avoidance of identified risks and the measurement of project outcomes.

Unlike previous studies that provide cross-sectional insight towards activities during GPD (Eppinger and Chitkara, 2009; Hansen and Ahmed-Kristensen, 2011), the current study is unique as it is one of very few longitudinal observational studies of real engineering design activities in the GPD environment. The following key contributions of the study are outlined:

- There is a need to support the development of preventive KPIs in the context of GPD that provide indication 
towards deviations before they arise, rather than solely outcome KPIs that provide a retrospective, time delayed outlook on performance that is typically used in conventional PD.

- The in-depth contextual understanding provides unique insight towards key risks encountered in GPD and their influence on project performance; an important step to support researchers and practitioners with the development of preventive measures.

- The study builds on previous studies that investigate the development and application of KPIs for conventional PD (O'Donnell and Duffy 2002; Tatikonda 2007) and business process in general (Mendibil and MacBryde 2007; Neely et al. 2000) by investigating this in the context of GPD.

- The KPI-DF builds on previous studies that highlight the need for practical frameworks to support management in overcoming the key risks in GPD (Eppinger and Chitkara 2009; Hansen and Ahmed-Kristensen 2011).

Although the in-depth nature of the study is a key strength, caution should be taken when generalizing the findings reported. The results of the empirical studies are derived from the analysis of multinational Danish manufacturing companies that recently took the decision to pursue GPD; hence, it makes sense to state that the findings are valid within this context. Furthermore, the case studies were conducted in their natural setting, which made it difficult to control single factors such as culture or distance that could otherwise have been controlled in a laboratory setting. Despite this, case studies carried out in their natural environment provide in-depth understanding of real-time tasks and activities that have been found to lead to creative insights of high validity for practitioners.

Building on this study, an interesting area for future research is to investigate the influence that managerial control has on project performance in the context of GPD. Balancing the level of control while providing global partners with sufficient responsibility towards development tasks remains a unique challenge for GPD. Furthermore, determining the long-term impact that using KPIs has on overall GPD success is an area that requires further research. To support these future research avenues, there exists a need for additional longitudinal observational studies that provide the necessary contextual understanding to trace problems back to their initial causes and provide in-depth understanding towards the application of KPIs in the GPD environment.

\section{Acknowledgments}

A special thanks go to the industrial partners for their time, information and willingness to participate in the study.

\section{Disclosure statement}

No potential conflict of interest was reported by the authors.

\section{Funding}

The authors would like to thank the Danish Industry Foundation for their support during the research.

\section{Notes on contributors}

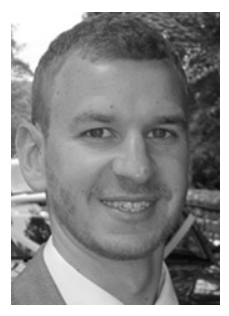

Thomas Paul Taylor is a postdoctoral researcher in the Management Engineering department of the Technical University of Denmark. His research is focused on distributed product development and the design and implementation of performance management and decision-support tools to support this. His research is carried out within the Innovation, Design and Entrepreneurship group and is co-funded by the Danish Industry Foundation. He employs empirical research methods in close collaboration with industry.

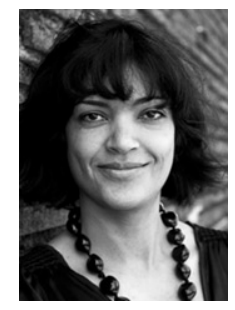

Saeema Ahmed-Kristensen, Ph.D., Professor, is currently a Chair in Design Engineering and Design Methodology and Deputy Head of the Dyson School of Design Engineering at Imperial College London. She is also a Tutor in the Innovation Design Engineering (IDE) and Global Innovation Design (GID) programme between Imperial College and the Royal College of Art. Saeema's research focuses upon improvements of both products (including product service systems) and processes (creative, product development and innovation) through developing a scientific understanding of the processes. She has over 100 reviewed publications and works in close collaboration with industry, from aerospace, oil drilling equipment, medical devices, to consumer products.

\section{Funding}

The authors would like to thank the Danish Industry Foundation for their support during the research.

\section{ORCID}

Saeema Ahmed-Kristensen (D) http://orcid.org/0000-0003-4035-7939

\section{References}

Aberdeen Group. 2005. The Global Product Design Benchmark Report. Massachusetts: Aberdeen Group, Inc.

Amaral, J., E. G. Anderson, and G. G. Parker. 2011. "Putting It Together: How to Succeed in Distributed Product Development." MIT Sloan Management Review 52 (2): 51-58.

Barr, S. 2014. Practical Performance Measurement: Using the PuMP Blueprint for Fast, Easy and Engaging KPIs. Australia: The PuMP Press.

Bierly, P. E., E. M. Stark, and E. H. Kessler. 2009. "The Moderating Effects of Virtuality on the Antecedents and Outcome of NPD Team Trust." Journal of Product Innovation Management 26 (5): 551-565. doi: 10.1111/j.1540-5885.2009.00680.x

Bonner, J. M., R. W. Ruekert, and, and C. O. Jr. Walker. 2001. "Upper Management Control of New Product Development Projects and Project Performance." Journal of Product Innovation Management 19 (3): 233-245.

Braun, V., and V. Clarke. 2006. "Using Thematic Analysis in Psychology." Qualitative Research in Psychology 3 (2): 77-101. doi:10.1191/ 1478088706qp063oa

Browning, T. R., J. J. Deyst, S. D. Eppinger, and D. E. Whitney. 2002. "Adding Value in Product Development by Creating Information and 
Reducing Risk." IEEE Transactions on Engineering Management 49 (4): 443-458. doi:10.1109/TEM.2002.806710

Bunduchi, R. 2013. "Trust, Partner Selection and Innovation Outcome in Collaborative New Product Development." Production Planning \& Control 24 (2-3): 145-157. doi:10.1080/09537287.2011.647868

BusinessWeek Research Services. 2006. "Global Product Development Moving from Strategy to Execution." PTC and BusinessWeek Research. http://www.cad-resources.com/Global-Product-Development.pdf.

Büyüközkan, G., and J. Arsenyan. 2012. "Collaborative Product Development: A Literature Overview." Production Planning \& Control 23 (1): 47-66. doi:10.1080/09537287.2010.543169

Cánez, L., K. Platts, and D. Probert. 2000. "Developing a Framework for Make-or-Buy Decisions." International Journal of Operations \& Production Management 20 (11): 1313-1330. doi:10.1108/ 01443570010348271

Carmel, E., J. Dedrick, and K. L. Kraemer. 2009. "Routinizing the Offshore Choice: Applying Diffusion of Innovation to the Case of EDS." Strategic Outsourcing: An International Journal 2 (3): 223-239. doi: 10.1108/17538290911005144

Cash, P., E. A. Dekoninck, and S. Ahmed-Kristensen. 2017. "Supporting the Development of Shared Understanding in Distributed Design Teams." Journal of Engineering Design 28 (3): 147-170. doi:10.1080/ 09544828.2016.1274719

Christodoulou, P., D. Fleet, and P. Hanson. 2007. Making the Right Things in the Right Places. Cambridge: Institute for Manufacturing.

Costa, H., J. Oehmen, E. Rebentisch, and D. Nightingale. 2014. "Toward a Better Comprehension of Lean Metrics for Research and Product Development Management." R\&D Management 44 (4): 370-383.

Crabtree, R. A., M. S. Fox, and N. K. Baid. 1997. "Case Studies of Coordination Activities and Problems in Collaborative Design." Research in Engineering Design 9 (2): 70-84. doi:10.1007/BF01596483

Driva, H., K. Pawar, and U. Menon. 2000. "Measuring Product Development Performance in Manufacturing Organisations." International Journal of Production Economics 63 (2): 147-159. doi: 10.1016/S0925-5273(99)00007-9

Emden, Z., R. J. Calantone, and C. Droge. 2006. "Collaborating for New Product Development: Selecting the Partner with Maximum Potential to Create Value." Journal of Product Innovation Management 23 (4): 330-341. doi:10.1111/j.1540-5885.2006.00205.x

Eppinger, S. D., and A. R. Chitkara. 2009. "The Practice of Global Product Development." IEEE Engineering Management Review 35 (1): 3-30.

Folan, P., and J. Browne. 2005. "Development of an Extended Enterprise Performance Measurement System." Production Planning and Control 16 (6): 531-544. doi:10.1080/09537280500112355

Ford, D. N., and J. D. Sterman. 2003. "The Liar's Club: Concealing Rework in Concurrent Development." Concurrent Engineering 11 (3): 211-219. doi:10.1177/106329303038028

Krishnan, V., and K. T. Ulrich. 2001. "Product Development Decisions: A Review of the Literature." Management Science 47 (1): 1-21. doi: 10.1287/mnsc.47.1.1.10668

Hansen, Z., and S. Ahmed-Kristensen. 2011. "Global Product Development: The Impact on the Product Development Process and How Companies Deal with It." International Journal of Product Development 15 (4): 205-226. doi:10.1504/IJPD.2011.044185

Hansen, Z., and S. Ahmed-Kristensen. 2012. Successful Global Product Development: A Guide for Industry. Copenhagen: Helstrup og Søn.

Hofstede, G., G. J. Hofstede, and M. Minkov. 2010. Cultures and Organisations: Intercultural Cooperation and Its Importance for Survival. USA: McGraw-Hill.

Ishikawa, A., and C. H. Smith. 1972. "A Feedforward Control System for Organizational Planning and Control." Abacus 8 (2): 163-180. doi: 10.1111/j.1467-6281.1972.tb00410.x

Kalyandurg, N., and K. B. Akhilesh. 2012. "Emerging Team Practices in Global Product Development." Strategic HR Review 11 (3): 143-149. doi:10.1108/14754391211216878

Kaplan, R. S., and D. P. Norton. 1996. "Linking the Balanced Scorecard to Strategy." California Management Review 39 (1): 53-79. doi:10.2307/ 41165876
Kaplan, R. S., and D. P. Norton. 1992. "The Balanced Scorecard: Measures That Drive Performance." Harvard Business Review 70 (1): 71-79.

Littler, D., F. Leverick, and M. Bruce. 1995. "Factors Affecting the Process of Collaborative Product Development: A Study of UK Manufacturers of Information and Communications Technology Products." Journal of Product Innovation Management 12 (1): 16-32. doi:10.1016/07376782(94)00025-B

Mcdonough, E. F., K. B. Kahn, and A. Griffin. 1999. "Managing Communication in Global Product Development Teams." IEEE Transactions on Engineering Management 46 (4): 375-386. doi:10.1109/ 17.797960

Mendibil, K., and J. MacBryde. 2007. "Designing Effective Team-Based Performance Measurement Systems: an Integrated Approach." Production Planning \& Control 16 (2): 208-225.

Neely, A., M. Gregory, and K. Platts. 2005. "Performance Measurement System Design: A Literature Review and Research Agenda." International Journal of Operations \& Production Management 25 (12): 1228-1263.

Neely, A., J. Mills, K. Platts, H. Richards, M. Gregory, M. Bourne, and M. Kennerley. 2000. "Performance Measurement System Design: developing and Testing a Process-Based Approach." International Journal of Operations \& Production Management 20 (10): 1119-1145. doi:10.1108/ 01443570010343708

Neely, A., M. Bourne, J. Mills, K. Platts, and H. Richards. 2002. Getting the Measure of Your Business. Cambridge: Cambridge University Press.

O'Donnell, F. J., and A. H. B. Duffy. 2002. "Modelling Design Development Performance." International Journal of Operations \& Production Management 22 (11): 1198-1221. doi:10.1108/ 01443570210450301

Poskela, J., and M. Martinsuo. 2009. "Management Control and Strategic Renewal in the Front End of Innovation." Journal of Product Innovation Management 26 (6): 671-684. doi:10.1111/j.15405885.2009.00692.x

Rhodes, D. H., R. Valerdi, and G. J. Roedler. 2009. " "Systems Engineering Leading Indicators for Assessing Program and Technical Effectiveness." Systems Engineering 12 (1): 21-35. doi:10.1002/ sys. 20105

Schein, E. H. 2004. Organizational Culture and Leadership. 3rd ed. San Francisco, USA: Jossey-Bass.

Siebdrat, F., M. Hoegl, and H. Ernst. 2009. "How to Manage Virtual Teams." MIT Sloan Management Review 50 (4): 63-68.

Snider, C., S. Škec, J. Gospill, and B. Hicks. 2016. "Determining work focus, common language, and issues in engineering projects through topic persistence." Paper presented at the International DESIGN Conference, Dubrovnik, May 16-19.

Tatikonda, M. V. 2007. "Product Development Performance Measurement." In Handbook of new product development management, edited by Christoph Loch and Stylianos Kavadias, 199-215. Abingdon: Routledge.

Toor, S., and S. Ogunlana. 2010. "Beyond the 'Iron Triangle': Stakeholder Perception of Key Performance Indicators (KPIs) for Large-Scale Public Sector Development Projects." International Journal of Project Management 28 (3): 228-236. doi:10.1016/j.ijproman.2009.05.005

Tripathy, A., and S. D. Eppinger. 2011. "Organizing Global Product Development for Complex Engineered Systems." IEEE Transactions on Engineering Management 58 (3): 510-529. doi:10.1109/TEM.2010. 2093531

Ulrich, K., and S. D. Eppinger. 2011. Product Design and Development. New York: McGraw-Hill Education.

Voss, C., N. Tsikriktsis, and M. Frohlich. 2002. "Case Research in Operations Management." International Journal of Operations \& Production Management 22 (2): 195-219. doi:10.1108/ 01443570210414329

Wang, J., W. Lin, and Y. Huang. 2010. "A Performance-Oriented Risk Management Framework for Innovative R\&D Projects." Technovation 30 (11-12): 601-611. doi:10.1016/j.technovation.2010.07.003 